\title{
CORRIGENDUM
}

\section{No asymmetry in geomagnetic reversals recorded by 1.1-billion-year-old Keweenawan basalts}

\author{
Nicholas L. Swanson-Hysell, Adam C. Maloof, Benjamin P. Weiss and David A. D. Evans
}

Nature Geoscience 2, 713-717 (2009); published online: 13 September 2009; corrected after print: 13 April 2010.

In the version of this Letter originally published, Supplementary Tables S2, S3 and S4 contained several errors. Consequently, the estimates of the rate of motion on page 716 should have read: "The estimates for the rate of motion from 1,108 Myr to 1,097 Myr range between $21.5 \pm 7.1 \mathrm{~cm} \mathrm{yr}^{-1}$ for Osler Volcanics reversed $\rightarrow$ North Shore normal, to $33.6 \pm 3.5 \mathrm{~cm} \mathrm{yr}^{-1}$ for Coldwell Complex reversed $\rightarrow$ North Shore normal." Furthermore, the position of the Duluth Complex reversed pole in Fig. 3a and the positions of the lower normal and upper normal palaeopoles in Fig. $3 \mathrm{~b}$ were slightly incorrect and should have been as shown here. These errors have been corrected in the HTML and PDF versions of the text.
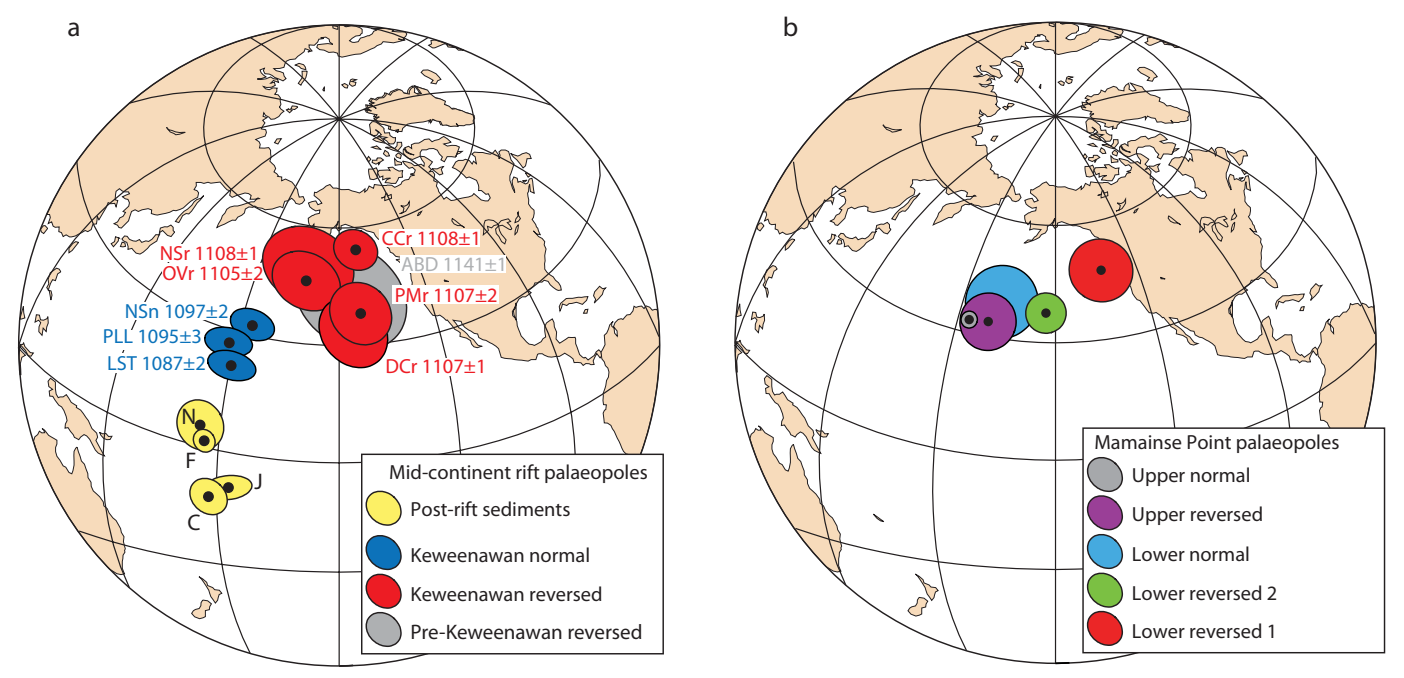